\title{
SINERGIA
}

\author{
REVISTA DO INSTITUTO DE CIÊNCIAS ECONÔMICAS, ADMINISTRATIVAS E CONTÁBEIS (ICEAC)
}

\section{DETERMINANTES DO EMPREENDEDORISMO NO RIO GRANDE DO SUL}

\author{
NICOLAS NUNES PAES \\ ROQUE PINTO DE CAMARGO NETO" \\ IGOR SERPA MORAES \\ GABRIELITO RAUTER MENEZES
}

\begin{abstract}
RESUMO
Há uma diversidade de estudos abordando os determinantes do empreendedorismo para países desenvolvidos, e, recentemente, alguns estudos abordam essa questão no Brasil. No entanto, existe uma lacuna em relação ao aspecto regional nessa abordagem. Portanto, este estudo tem como objetivo contribuir para a literatura com uma análise dos determinantes do empreendedorismo para o estado do Rio Grande do Sul. Para isso, faz-se uso dos microdados da Pesquisa Nacional de Amostra por Domicílio de 2015, bem como de um modelo de escolha discreta probit. Os principais resultados encontrados apontam que os atributos pessoais (sexo, raça, idade e educação), as características familiares (estado civil e se é chefe de família), os aspectos relacionados à renda (se é aposentado e se recebe renda de aluguel) e questões demográficas (se reside em área urbana ou em área metropolitana) são relevantes para um indivíduo determinar a escolha ocupacional empreendedora no estado do Rio Grande do Sul.
\end{abstract}

Palavras-chave: Empreendedorismo; Mercado de Trabalho; Rio Grande do Sul; Probit; Escolha Ocupacional.

\section{ABSTRACT}

There is a diversity of studies addressing the determinants of entrepreneurship for developed countries, and recently some studies addressing this issue in Brazil. However, there is a gap with the regional aspect of this approach. Therefore, this study aims to contribute to the literature with an analysis of the determinants of entrepreneurship for the state of Rio Grande do Sul, using the microdata of the National Household Sample Survey of 2015, as well as a discrete probit choice model. The main results show that the personal attributes (gender, race, age and education), family characteristics (marital status and family head), aspects related to income (if retired and rent income) and (whether residing in urban or metropolitan area) are relevant for an individual to determine the entrepreneurial occupational choice in the state of Rio Grande do Sul.

Keywords: Entrepreneurship; Job market; Rio Grande do Sul; Probit; Occupational Choice.

Recebido em: 13-02-2019 Aceito em: 29-04-2019

\section{INTRODUÇÃO}

Para Schumpeter (1934), o empreendedor é o grande responsável pela criação de novos produtos ou de novos meios de produção, fatores esses que conduzem ao desenvolvimento econômico. Oitenta e cinco anos se passaram desde essa publicação, mas o tema continua atual. Há uma diversidade de problemáticas e novas ferramentas para abordar o assunto. No Brasil, a discussão é recente, poucos estudos buscam avaliar os fatores socioeconômicos e comportamentais que levam os indivíduos a optarem pela ocupação empreendedora. É imprescindível para que, assim, haja eficiência nas políticas públicas que visam incentivar o empreendedorismo no país.

Segundo Menezes (2015), a microeconomia oferece os conceitos para analisar as decisões da ocupação empreendedora, mostrando-se extremamente eficaz na leitura das variáveis que influenciam na escolha ocupacional, e definem que, pela ótica da economia, os agentes preferem o empreendedorismo ao ser empregado, dado que maximizem sua utilidade esperada. Nesse sentido, pesquisas empíricas na investigação da escolha ocupacional indicam a fundamentação no raciocínio comportamental e econômico do agente, levando em conta decisões ótimas em relação aos fatores demográficos e econômicos (CÉSPEDES; FOCHEZATTO, 2016).

\footnotetext{
"Graduando em Ciências Economia pela Universidade Federal do Rio Grande. E-mail: nicolasnpaes@hotmail.com

".* Mestre em Economia Aplicada e Graduado em Ciências Econômicas pela Universidade Federal do Rio Grande.

.*.* Mestre em Economia Aplicada e Graduado em Ciências Econômicas pela Universidade Federal do Rio Grande.

"Doutor em Economia Aplicada pela Universidade Federal do Rio Grande do Sul.
} 
Baseado nas teorias de escolha ocupacional, pela alocação de talento empreendedor e pela força de trabalho, Lucas (1978) destacou que os indivíduos se diferenciam em aspectos da sua capacidade empreendedora, sendo esta característica a base da heterogeneidade dos agentes no modelo. Ou seja, os agentes objetivam a escolha de acordo com a profissão que thes otimizará a utilidade esperada. Os indivíduos com habilidades comuns permanecem empregados, e os com maior capacidade (empreendedora) tornam-se empreendedores.

Reynolds et al. (1994) realizam um denso estudo sobre as características pessoais dos empreendedores que alcançaram o sucesso, destacando visão e gestão de negócios, proatividade na prospecção de oportunidades, experiência profissional, origem étnica e nível de estudos. Segundo Lee (2004),constata-se que a opção pela ocupação empreendedora pode ter relação com a origem étnica. Seu trabalho revela que coreanos e judeus têm mais êxito nos negócios do que a população afro-americana, pois possuem maior acesso ao capital via heranças, ligações familiares e étnicas. Yoon (1997) sugere que, por necessidade, imigrantes sofrem com discriminação, cultura e comunicação diferentes. Dessa forma, são "forçados" a empreender e/ou tornarem-se autônomos.

Para Parker (2004), outras variáveis têm grande impacto sobre a escolha ocupacional, sendo elas características únicas do indivíduo, como educação, capital humano, idade, personalidade e aversão ao risco. De acordo com Fritsch e Rusakova (2011), os níveis de capital humano são mensurados de acordo com os anos de formação acadêmica ou profissional, tornando os agentes mais assertivos quanto ao reconhecimento e à execução de projetos ou oportunidades, capacitando-Ihes para serem empreendedores. Os estudos de Rees e Shah (1986), Taylor (1996), Blanchflower e Meyer (1994) e Blanchflower (2000) concluem a existência de relação positiva entre educação e a decisão de ser empreendedor. Em contraponto, Blanchflower et al. (2001) encontraram relações negativas entre as variáveis. Não havendo, assim, consenso teórico sobre a influência da educação na escolha ocupacional (MENEZES, 2015).

O gênero do indivíduo também se mostra importante para a análise dos determinantes do empreendedorismo. A mulher possui menor probabilidade em ser empreendedora, quando comparada ao homem (BLANCHFLOWER, 2000; CAMARGO NETO et al., 2017; MENEZES, 2015). Nesse sentido, Bernat et al. (2016) buscam identificar um conjunto de fatores associados à decisão de se tornar um empreendedor e as variáveis que explicam a diferença de gênero na atividade empreendedora na América Latina. Os autores encontram que os fatores que explicam tanto a atividade empreendedora quanto o hiato de gênero: educação, tolerância ao risco, carro próprio como principal meio de transporte e satisfação no trabalho.

O estudo de Menezes (2015) busca não só avaliar o efeito das características socioeconômicas sobre os determinantes do empreendedorismo no Brasil, bem como o diferencial de salário entre empreendedores e assalariados, fator importante para a escolha ocupacional empreendedora. Nesse sentido, Camargo Neto et al. (2017) também avaliam os determinantes do empreendedorismo no Brasil, sob uma ótica regional, e apontam que o aspecto regional exerce influência sobre a escolha ocupacional empreendedora. Tendo isso em vista, este estudo tem como objetivo avaliar os determinantes do empreendedorismo no Rio Grande do Sul. Com isso, busca-se contribuir para a literatura no sentido de analisar o empreendedorismo em âmbito regional, e, com isso, dar mais robustez aos resultados encontrados por Camargo Neto et al. (2017), tendo em vista a heterogeneidade socioeconômica entre as regiões brasileiras.

Sobre o empreendedorismo gaúcho, Höher et al. (2017)destacam que regiões do Rio Grande do Sul onde a população apresenta maior nível educacional e renda per capita, bem como com baixa taxa de desocupação são propensas a serem mais empreendedoras que outras, destacando-se a serra gaúcha e litoral norte nesses quesitos. Além disso, citam que localidades que apresentam alto índice de desemprego são menos empreendedoras. Nesse sentido, Céspedes e Fochezatto (2016) também avaliam os determinantes do empreendedorismo no Rio Grande do Sul. E apontam que o nascimento de novas empresas é relativamente mais alto em lugares com altas taxas de crescimento populacional e com tamanho médio dos estabelecimentos maior.

Com base nos dados do GEM (2015), os empreendedores gaúchos representam $26 \%$ da população de 18 a 64 anos, o que corresponde a mais de 1,9 milhão de pessoas. Os dados da Pesquisa Nacional de Amostra por Domicílios (PNAD) de 2015 vão de encontro a essas informações (25,81\%). Portanto, cabe o seguinte questionamento: as características socioeconômicas e regionais afetam a escolha ocupacional empreendedora no Rio Grande do Sul? Para responder a esse problema de pesquisa, o presente estudo não só adota um modelo de escolha ocupacional binário, estimado por um probit, bem como utiliza os microdados da PNAD (2015).

Além desta introdução, o estudo está dividido em uma segunda seção que aborda os materiais e métodos utilizados, uma terceira seção que aborda os resultados e discussões e, por fim, a última seção, com as considerações finais. 


\section{MATERIAIS E MÉTODOS}

\subsection{Base de dados}

Para responder ao problema de pesquisa apresentado na introdução deste estudo, faz-se uso dos microdados da Pesquisa Nacional por Amostra por Domicílios (PNAD) do ano de 2015, elaborada pelo Instituto Brasileiro de Geografia e Estatística (IBGE). Cabe ressaltar que os dados são baseados em um processo de amostragem complexo, possui estratificação, conglomeração e probabilidades desiguais de seleção. Portanto, é necessário se declarar no modelo como uma amostra complexa; caso contrário, gerará viés nos resultados (SANTOS et al., 2010). Conforme a tabela 1, pode-se verificar a descrição e estatísticas descritivas das variáveis selecionadas, bem como as suas descrições.

TABELA 1 - Estatísticas descritivas

\begin{tabular}{|c|c|c|c|c|}
\hline Atributos pessoais & Descrição & Média & Desvio-Padrão & Observações \\
\hline Sexo & 1: Homem; 0: Mulher & 0,5823 & 0,4932 & 10.325 \\
\hline Raça & 1: Branco; 0: Outras & 0,8058 & 0,3955 & 10.325 \\
\hline Idade & Anos & 39,5840 & 13,0635 & 10.325 \\
\hline Idade $^{2}$ & Idade ao quadrado & 1737,534 & 1101,3 & 10.325 \\
\hline Educação & Anos de estudo & 10,6016 & 3,7690 & 10.325 \\
\hline \multicolumn{5}{|l|}{ Família } \\
\hline Vive com cônjuge & 1: Vive com cônjuge; 0: Outros & 0,0288 & 0,1674 & 10.325 \\
\hline Chefe & 1: Chefe; 0 : Outros & 0,5132 & 0,4998 & 10.325 \\
\hline № de filhos & Número de filhos & 0,3683 & 0,7686 & 10.325 \\
\hline \multicolumn{5}{|l|}{ Renda } \\
\hline Pensionista & $\begin{array}{l}\text { Se recebeu renda } \\
\text { como pensionista }\end{array}$ & 0,0148 & 0,1208 & 10.325 \\
\hline Aposentado & $\begin{array}{l}\text { Se recebeu renda } \\
\text { como aposentado }\end{array}$ & 0,0711 & 0,2571 & 10.325 \\
\hline Renda outros & Se recebeu outros tipos de renda & 0,2713 & 0,1619 & 10.325 \\
\hline Renda aluguel & $\begin{array}{l}\text { Se recebeu renda proveniente } \\
\text { de aluguel }\end{array}$ & 0,0101 & 0,1003 & 10.325 \\
\hline \multicolumn{5}{|c|}{ Variáveis Demográficas } \\
\hline Urbano & Se reside em área urbana & 0,9215 & 0,268 & 10.325 \\
\hline Metrópole & Se reside em área metropolitana & 0,6596 & 0,4738 & 10.325 \\
\hline
\end{tabular}

FONTE: Elaborado pelos autores a partir dos dados da PNAD 2015 - IBGE.

Adotam-se alguns recortes necessários na amostra: a utilização apenas das informações contidas para o estado do Rio Grande do Sul, a exclusão dos indivíduos sem observação de renda e daqueles com salário abaixo de $\mathrm{R} \$ 700,00$ e acima de $\mathrm{R} \$ 50.000,00$, a condição econômica dos indivíduos "desocupados", a posição dos agentes na ocupação de trabalho militar, servidor público estatutário e menores de 15 anos e com mais de 90 anos. O recorte amostral de idade é necessário, tendo em vista os indivíduos não possuírem condições de ocupação no mercado de trabalho.

As variáveis utilizadas para analisar os determinantes do empreendedorismo são: atributos pessoais (sexo, raça, idade, idade ao quadrado e educação), as características familiares (estado civil, se é chefe de família e número de filhos), os aspectos relacionados à renda (se é aposentado, se é pensionista, se recebe renda de aluguel e outros tipos de renda) e questões demográficas (se reside em área urbana ou em área metropolitana). As variáveis estão de acordo com a literatura sobre economia do empreendedorismo (CAMARGO NETO et al., 2017; MENEZES, 2015; PARKER, 2018).

As variáveis são apresentadas na forma descritiva na tabela 2, subdivididas pela ocupação e gênero dos indivíduos. A amostra final para o período analisado tem um número total de 10.325 indivíduos. Desses, 6.324 indivíduos responderam à pesquisa como assalariados com carteira; enquanto 1.336 se reportaram como assalariados sem carteira. Ressalta-se que 2.665 indivíduos se reportaram como empreendedores, ou seja, representa a junção dos trabalhadores por conta própria mais empregadores. Do total de agentes da amostra, $6.046(58,56 \%)$ são homens, e 4.279 (41,44\%) são mulheres, indicando uma maior participação dos homens no mercado de trabalho. 
TABELA 2 - Número e percentual dos indivíduos da amostra por ocupação e gênero

\begin{tabular}{lcccccc}
\hline \multicolumn{1}{c}{ Ocupação } & Total & Homem & Mulher & Total \% & Homem \% & Mulher \% \\
\hline Assalariado com carteira & 6.324 & 3.445 & 2.879 & 61.25 & 54.4 & 45.52 \\
Assalariado sem carteira & 1.336 & 717 & 619 & 12.94 & 53.67 & 46.33 \\
Empreendedor & 2.665 & 1.884 & 781 & 25.81 & 70.53 & 29.47 \\
Total & 10.325 & 6.046 & 4.279 & 100 & 58.56 & 41.44
\end{tabular}

FONTE: Elaborado pelos autores a partir dos dados da PNAD 2015 - IBGE.

\subsection{Estratégia Empírica}

Parte-se do pressuposto da teoria econômica de que o agente escolhe a alternativa que maximiza a sua utilidade, sendo que esta escolha é, muitas vezes, entre fazer ou não alguma ação, como, por exemplo, ser ou não empreendedor. Essas são escolhas binárias, e as variáveis acabam por assumir valores de "zero ou um", ou seja, valores para "sim ou não". Segundo Parker (2004, 2009), modelos binários são muito utilizados para se realizar estudos sobre empreendedorismo, modelando-o como escolha ocupacional, sendo os mais conhecimentos o logit e o probit. Neste caso, adota-se a seguinte decisão: empreender ou ser assalariado. A variável dependente é binária, em que:

$$
y_{i}=\left\{\begin{array}{l}
1: \text { se é empreendedor } \\
0: \text { se é assalariado }
\end{array}\right.
$$

O probit assume, como variável latente não observável, o termo erro com distribuição normal padrão e independente da variável dependente $X$, com média zero e variância constante, assim, o erro é simetricamente distribuído ao redor de zero (WOOLDRIDGE, 2010). A função de distribuição acumulada (FDA) normal padronizada, em que $\circ X$ possui distribuição normal, média $\mu$ e variância $\sigma^{2}$, é dada por (GUJARATI; PORTER, 2011):

$$
f(x)=\int_{-\infty}^{x_{0}}{\frac{1}{\sqrt{2 \sigma^{2} \pi}}}^{-\frac{(x-\mu)^{2}}{2 \sigma^{2}}}
$$

A probabilidade de uma escolha $\mathrm{P}(\mathrm{Y}=1)$ é influenciada por um índice de utilidade não observável $I i$, que é determinada por uma ou várias variáveis independentes. Quanto maior o valor do índice, maior a probabilidade de o agente escolher pelo empreendedorismo, conforme a equação:

$$
I i=\beta_{1}+\beta_{2} X_{i}
$$

É factível de se inferir que haja para cada indivíduo um nível crítico ou limiar do índice, $I i^{\star}$, tal que, se $I i$ superar $I i^{\star}$, o agente escolherá pelo empreendedorismo, caso contrário, não. O $I i^{*}$, igual ao $I i$, é não observável. Admitindo que se distribui normalmente e com mesma média e variância, é possível de se obter não somente a estimação dos parâmetros do índice, mas também alguma informação do índice não observável.

Portanto, seguindo o conceito de distribuição normal, a probabilidade $P$ de $Y$ ser empreendedor $\left(I i^{*} \leq I i\right)$, dada a função probit $F$, ou seja, a função distributiva normal padronizada, é dada por:

$$
P i=P(Y=1 \mid X)=P(I i * \leq I i)=(Z i \leq \beta 1+\beta 2 X i)=F(\beta 1+\beta 2 X i)
$$

Em que $\mathrm{P}(\mathrm{Y}=1)$ é a probabilidade de o agente optar pelo empreendedorismo, de acordo com os valores das variáveis independes, e $Z i$ é a variável normal padrão $Z \sim N\left(0, \sigma^{2}\right)$, com média zero e variância constante. A FDA normal padronizada, dada a probabilidade de $I i^{*} \leq I i$ é:

$$
\begin{aligned}
& f(I i)=\frac{1}{\sqrt{2 \pi}} \int_{-\infty}^{I i} e^{-z^{2} / 2 d z} \\
& =\frac{1}{\sqrt{2 \pi}} \int_{-\infty}^{\beta 1+\beta 2 X i} \mathrm{e}^{-z^{2} / 2} \mathrm{dz}
\end{aligned}
$$


A probabilidade de o agente se tornar empreendedor é medida pela área da curva normal padrão de $-\infty$ a Ii. Ao se utilizar o inverso da equação anterior, pode se obter informações sobre $\mathrm{I}_{i}$, como sobre $\beta_{1} \mathrm{e} \beta_{2}$ :

$$
\begin{aligned}
& \mathrm{I}_{i}=\mathrm{F}^{-1}\left(\mathrm{I}_{i}\right)=\mathrm{F}^{-1}\left(\mathrm{P}_{i}\right) \\
& =\beta_{1}+\beta_{2} \chi_{i}
\end{aligned}
$$

O probit assume, como variável latente não observável, o termo erro, com distribuição normal padrão e independente da variável dependente $X$, com média zero e variância constante; assim, o erro é simetricamente distribuído ao redor de zero (WOOLDRIGDE, 2010). Para realizar a regressão, o modelo utiliza o procedimento de máxima verossimilhança; e este processo seleciona estimativas dos parâmetros desconhecidos de modo a maximizar o valor da função de verossimilhança.

Os coeficientes estimados pelo método de máxima verossimilhança não nos permitem realizar uma interpretação direta dos coeficientes. Portanto, estima-se o efeito marginal médio, ou seja, o efeito marginal calculado com os valores médios da amostra, pois os seus resultados permitem analisar inferências quantitativas dos coeficientes estimados (MENEZES, 2015), tendo resultados em valores percentuais das variáveis na probabilidade de o indivíduo optar pelo empreendedorismo.

\section{RESULTADOS E DISCUSSÃO}

No geral, os resultados encontrados estão de acordo com o esperado. O resultado do teste chiquadrado indica que as variáveis explicativas são importantes para explicar a variável dependente. Verificou-se que somente as variáveis idade ao quadrado, número de filhos, se é pensionista e se recebe outros tipos de rendas não são estatisticamente significativas. Ser aposentado é estatisticamente significativo a $95 \%$ de confiança, e todas as demais variáveis são estatisticamente significativas a $99 \%$ de confiança. Pode-se observar que o modelo apresentou um bom ajustamento, uma vez que, via tabela de classificação preditiva, o modelo prevê corretamente $76,72 \%$ dos eventos.

Os resultados indicam que os indivíduos do sexo masculino têm maior probabilidade de se tornarem empreendedores $(11,26 \%)$ em relação ao sexo feminino. Nesse sentido, corrobora com os trabalhos de Wit e Winden (1990), Menezes (2015), Camargo Neto et al. (2017) e Blanchflower (2000), que apontam maiores chances de os homens optarem pelo empreendedorismo. Quanto à raça, indivíduos de cor branca possuem 6,93\% a mais na probabilidade de empreender do que outras raças (variável omitida), o que também reflete o trabalho de Borjas e Bronars (1989), Menezes (2015) e Camargo Neto et al. (2017), que indicam que os agentes de outras raças possuem menos incentivos a empreender do que os brancos.

A idade é correlacionada ao ganho de capital em experiência de mercado e tem resultado positivo em $0,83 \%$, ou seja, quanto maior a idade, mais experiência e maiores chances de um indivíduo optar pela ocupação empreendedora, o que corrobora com Calvo e Wellizs (1980), Rees e Shah (1986), Blanchflower (2000), Menezes (2015) e Camargo Neto et al. (2017). Entretanto, os resultados da idade ao quadrado não foram significativos no modelo para o Rio Grande do Sul, o que difere dos trabalhos de Menezes (2015) e Camargo Neto et al., (2017), que encontram comportamento não linear para esta variável, o que indica que a probabilidade de se tornar empreendedor aumenta com a idade, mas até um certo ponto e depois começa a diminuir de acordo com a idade, o que corrobora com Parker (2009) e Evans e Leighton (1989). 
TABELA 3 - Determinantes do Empreendedorismo no Rio Grande do Sul

\begin{tabular}{|c|c|c|}
\hline \multirow{2}{*}{ Variáveis } & \multicolumn{2}{|c|}{ Modelo Probit } \\
\hline & Coeficiente & Efeito Marginal \\
\hline \multirow[t]{2}{*}{ Sexo } & $0.3854^{* * *}$ & $0.1126^{\star * *}$ \\
\hline & $(0.0479)$ & $(0.0142)$ \\
\hline \multirow[t]{2}{*}{ Raça } & $0.2371^{* * *}$ & $0.0693^{* * *}$ \\
\hline & $(0.0470)$ & $(0.0136)$ \\
\hline \multirow[t]{2}{*}{ Idade } & $0.0284^{* * *}$ & $0.0083^{* * *}$ \\
\hline & $(0.0090)$ & $(0.0026)$ \\
\hline \multirow[t]{2}{*}{ Idade ao quadrado } & 0.000 & 0.0000 \\
\hline & $(0.0001)$ & $(0.0000)$ \\
\hline \multirow{2}{*}{ Educação } & $0.0312^{\star * *}$ & $0.0091^{* * *}$ \\
\hline & $(0.0058)$ & $(0.0017)$ \\
\hline \multirow[t]{2}{*}{ Estado civil } & $0.1773^{\star \star *}$ & $0.0518^{\star * *}$ \\
\hline & $(0.0908)$ & $(0.0107)$ \\
\hline \multirow[t]{2}{*}{ Chefe } & $0.1271^{* * *}$ & $0.0389^{* * *}$ \\
\hline & $(0.0412)$ & $(0.0119)$ \\
\hline \multirow[t]{2}{*}{$N^{\circ}$ de filhos } & 0.0099 & -0.0029 \\
\hline & $(0.0320)$ & $(0.0093)$ \\
\hline \multirow[t]{2}{*}{ Pensionista } & 0.0 .0649 & 0.0189 \\
\hline & $(0.1321)$ & $(0.0386)$ \\
\hline \multirow[t]{2}{*}{ Aposentado } & $-0.1771^{* *}$ & $-0.0517^{* *}$ \\
\hline & $(0.0750)$ & $(0.0218)$ \\
\hline \multirow[t]{2}{*}{ Renda aluguel } & $0.4542^{* * *}$ & $0.1327^{\star * *}$ \\
\hline & $(0.1374)$ & $(0.0401)$ \\
\hline Renda outro & $\begin{array}{l}-0.0076 \\
(0.1002)\end{array}$ & $\begin{array}{c}-0.0022 \\
(0.0293)\end{array}$ \\
\hline \multirow{2}{*}{ Urbana } & $-0.5579^{* * *}$ & $-0.1630^{\star * *}$ \\
\hline & $(0.0779)$ & $(0.0221)$ \\
\hline \multirow{2}{*}{ Metrópole } & $-0.2150^{\star \star *}$ & $-0.0628^{\star \star *}$ \\
\hline & $(0.0368)$ & $(0.0110)$ \\
\hline Constante & $-2.1875^{\star \star *}$ & \\
\hline Observações & $\frac{(0.2053)}{10,325}$ & 10,325 \\
\hline Classificação preditiva & $76.72 \%$ & \\
\hline
\end{tabular}

Com isso, obtém-se que indivíduos mais velhos possuem maiores probabilidades em se tornarem empreendedores, como pode-se notar na Figura 1. O acréscimo da idade afeta positivamente a probabilidade de um indivíduo ser empreendedor.

FIGURA 1 - Acréscimo da idade em função da probabilidade de empreender

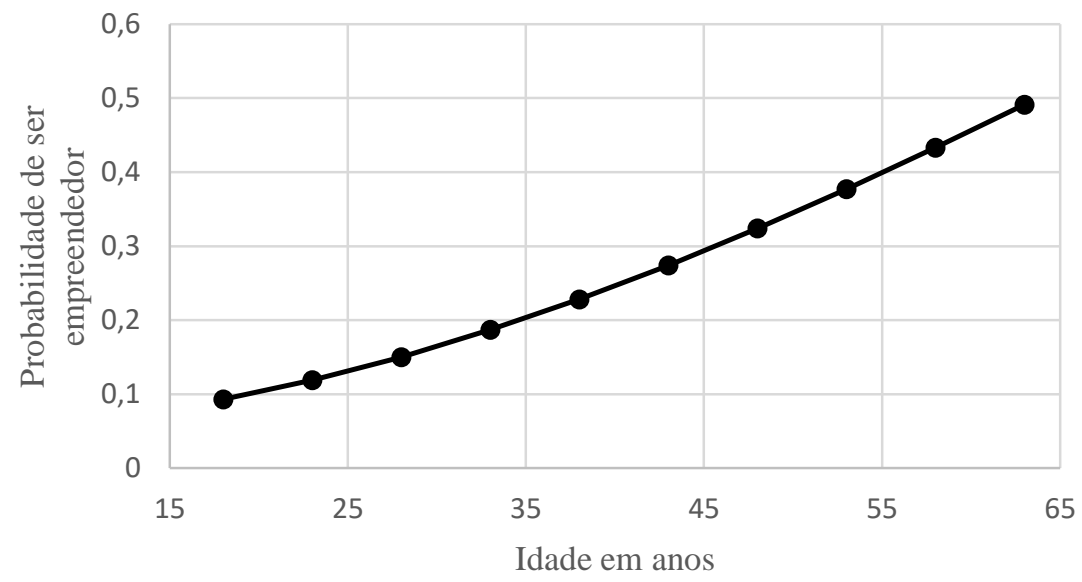

FONTE: Elaborado pelos autores. 
Com relação ao estado civil, tem-se que indivíduos que vivem com os cônjuges têm uma probabilidade maior em se tornarem empreendedores $(5,18 \%)$ em relação aos demais. $O$ que corrobora com os resultados de Gill (1988), Borjas (1986), Rees et al. (1986), Blanchflower et al. (1998) e Menezes (2015) que indicam a possibilidade de a formação do casal acumular maior montante de capital, apoio emocional e uma segunda renda para maior segurança em caso de insucesso. No sentido contrário, os resultados de Dolton e Makepeace (1990) indicam que o indivíduo casado possui maiores responsabilidades de sustento da família, tendo, portanto, uma influência negativa. E por fim, Camargo Neto et al. (2017) não encontraram resultados significativos para essa questão.

Ser chefe de família aumenta as chances de um indivíduo empreender, cerca de 3,89\%. Esse fato pode estar relacionado ao empreendedorismo por necessidade, tendo em vista a necessidade de sustentar a família. Esse resultado converge com Lindh e Ohlsson (1996), Menezes (2015) e Camargo Neto et al. (2017). No entanto, Holtz-Eakin et al. $(1993,1994)$ indicam que os empreendedores estão mais propensos a focar em maiores ganhos do que na constituição familiar.

As variáveis de analise por localização, ou seja, localização espacial onde os indivíduos residem é representada por urbana e metrópole. Respectivamente, elas geraram resultados negativos na probabilidade em se tornar empreendedor, sendo a primeira em $-16,30 \%$ e a segunda em $-6,28 \%$. Resultados convergem com os encontrados por Menezes(2015) e Camargo Neto et al. (2017) para o Brasil e para as cinco macrorregiões, o que indica que indivíduos que residem em áreas urbanas ou metropolitanas possuem maior oferta de empregos e oportunidades, bem como maiores salários, dessa forma, possuem mais incentivos para não empreender.

Os resultados das variáveis relacionadas à renda apresentaram resultados significativos para renda de aluguel em 13,27\%, o que converge com estudos de Blanchflower e Oswald (1998), Evans e Leighton (1989), Hammarstedt (2009), que indicam relação positiva entre renda provida até mesmo de herança e a probabilidade em se tornar empreendedor. Entretanto, ser aposentado apresentou um resultado negativo de $5,17 \%$ em relação à probabilidade em se tornar empreendedor, que difere dos trabalhos de Menezes (2015) e Camargo Neto et al. (2017), nos quais este trabalho se baseia, evidenciando a necessidade de se estudar a relação de cada variável em estados diferentes.

Por fim, a variável anos de estudos é analisada como variável de capital humano. Portanto, tem um comportamento positivo na probabilidade de um indivíduo ser empreendedor. Nota-se, a partir da figura 2, a existência desta relação no estado do Rio Grande do Sul. A variável gerou resultados significativos em $0,91 \%$ na probabilidade de se optar pela ocupação empreendedora, o que compactua com os resultados de Sluis et al.(2005)e Bates (1990), nos quais evidenciam que os maiores níveis de escolaridade contribuem para a estruturação, planejamento, e assim, para o sucesso dos novos negócios. Além disso, os resultados convergem para os resultados de Höher et al. (2017), de que a educação tem um papel importante para o empreendedorismo no estado do Rio Grande do Sul.

FIGURA 2 - Acréscimo dos anos de estudo em função da probabilidade de empreender

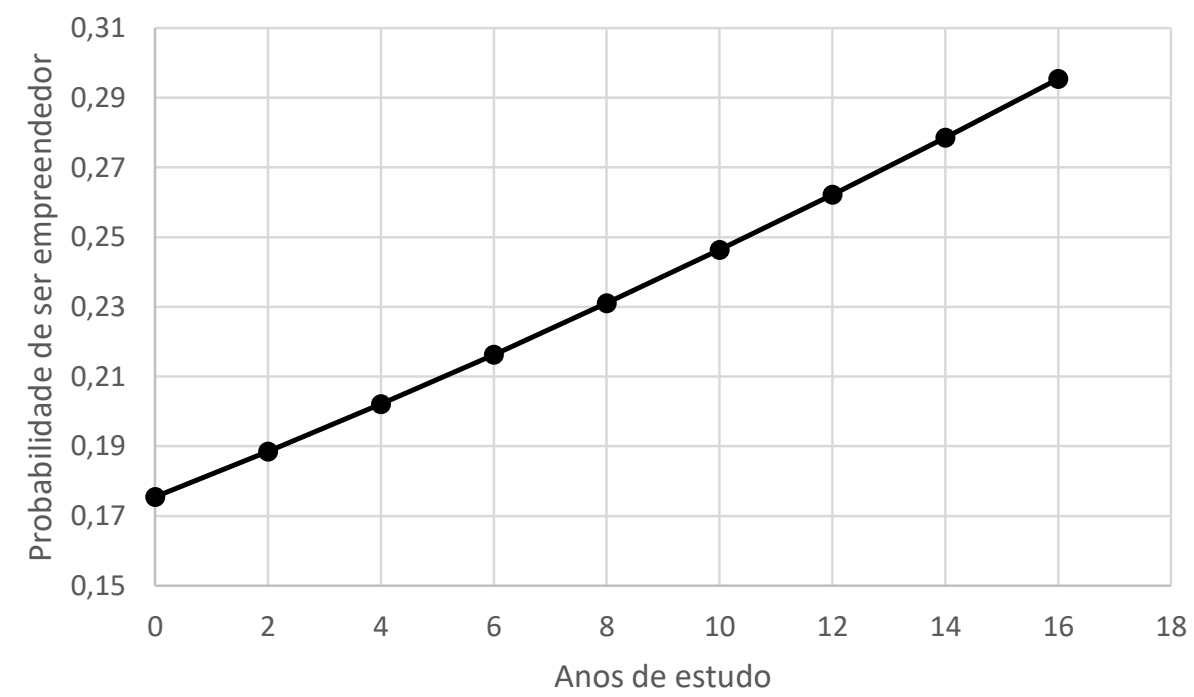

FONTE: Elaborado pelos autores.

Rees e Shah (1986) ressaltam que a educação influencia, positivamente, a probabilidade em se optar pela ocupação empreendedora e aumenta a produtividade, e, por consequência, o salário do indivíduo, elevando o seu custo de oportunidade em empreender. A relação entre a escolaridade e a opção 
empreendedora também é encontrada por Menezes (2015),cujos resultados indicam que, ao aumentar os níveis de escolaridade, a probabilidade em se tornar empreendedor é negativa para os níveis educacionais ensino médio e superior. Nesse sentido, Blanchflower et al. (2001)apontam uma relação negativa entre a variável educação e a probabilidade de se tornar empreendedor em países desenvolvidos. Por fim, Camargo Neto et al. (2017) encontraram que a escolaridade afeta positivamente a probabilidade de um indivíduo ser empregador, e, na contramão, afeta negativamente a probabilidade de um indivíduo ser autônomo. O que faz sentido, tendo em vista que os autônomos podem representar o empreendedorismo por necessidade, sendo assim, a escolaridade pode contribuir para que esses indivíduos consigam uma colocação como assalariados no mercado de trabalho ou para que busquem ampliar o negócio e assim passarem de autônomos para empregadores.

\section{CONSIDERAÇÕES FINAIS}

A esfera da economia do empreendedorismo proporciona insights sobre os determinantes individuais da escolha pela ocupação empreendedora. Este trabalho buscou analisar quais são os fatores determinantes que levam o indivíduo a fazer uma escolha de se tornar ou não um empreendedor para o estado do Rio Grande do Sul.

Pode-se constatar a importância do empreendedorismo no crescimento e no desenvolvimento econômico dos países, no sentido de gerar novas tecnologias, maior produtividade de trabalho e de geração deste. Outro importante indício é de que o grande desafio está no ambiente microeconômico, para se compreender o comportamento e influência das variáveis que impactam na probabilidade em se tornar empreendedor.

De acordo com os resultados, os determinantes do empreendedorismo no Rio Grande do Sul são influenciados por variáveis socioeconômicas, demográficas, bem como características próprias de cada indivíduo. O modelo probit, utilizado para estimar a escolha ocupacional dos agentes, indicou resultados significativos para: atributos pessoais (sexo, raça, idade e educação), as características familiares (estado civil e se é chefe de família), os aspectos relacionados à renda (se é aposentado e se recebe renda de aluguel) e questões demográficas (se reside em área urbana ou em área metropolitana).

Cabe ressaltar sobre algumas limitações deste estudo. A primeira está relacionada à variável dependente. Ao agregar empregadores e autônomos, pode-se gerar alguns efeitos ambíguos, principalmente se houver características que possam influenciar de forma oposta, tendo em vista que os empregadores podem ser uma proxy para o empreendedorismo por oportunidade, bem como os autônomos para o empreendedorismo por necessidade. Além disso, a segunda limitação está na base de dados, já que os questionários não são voltados, especificamente, para a questão do empreendimento, e, sim, uma pesquisa abrangente que busca captar uma diversidade de informações.

Por fim, pode-se evidenciar algumas contribuições que podem ser utilizadas para formulação de políticas públicas que incentivem e facilitem o aumento da iniciativa de se tornar empreendedor, como, por exemplo: menores impostos, menor burocracia na abertura de novos negócios e até mesmo linhas de crédito mais acessíveis. Além disso, pode-se compreender quais são os principais fatores socioeconômicos que influenciam a escolha pela ocupação empreendedora, servindo como subsídio para políticas púbicas que visam incentivar o empreendedorismo no Estado gaúcho. Reforçando que este grupo econômico, por muitas vezes, é uma alternativa importante para geração de renda e emprego em momentos de crise econômica, como o vivido no atual momento da economia gaúcha. Deixa-se como proposta de extensão para estudos futuros a estimação das equações de rendimento e o diferencial de salário dos agentes no Rio Grande do Sul, por meio de modelos de Heckman e Oaxaca Blinder.

\section{REFERÊNCIAS}

BATES, Timothy. Entrepreneur Human Capital Inputs and Small Business Longevity. The Review of Economics and Statistics, [s. I.], v. 72, n. 4, p. 551, 1990. Disponível em: <https://www.jstor.org/stable/2109594?origin=crossref>. Acesso em: 4 dez. 2018.

BERNAT, Luisa Fernanda; LAMBARDI, German; PALACIOS, Paola. Determinants of the entrepreneurial gender gap in Latin America. Small Business Economics, [s. I.], v. 48, n. 3, p. 727-752, 2016.

BLANCHFLOWER, D. G.; OSWALD, A. J. What Makes an Entrepreneur. Labour economics, [s. I.], v. 16, n. 1, p. 26-60, 1998.

BLANCHFLOWER, David G. Self-employment in \{OECD\} countries. Labour economics, [s. I.], v. 7, n. 5, p. 471-505, 2000.

BLANCHFLOWER, David G.; EVANS, David S.; OSWALD, Andrew J. Credit cards and entrepreneurship. National Economic Research Associates, [s. I.], v. 1, 1998.

BLANCHFLOWER, David G.; MEYER, Bruce D. A longitudinal analysis of the young self-employed in Australia and the United States. Small Business Economics, [s. I.], v. 6, n. 1, p. 1-19, 1994. 
BLANCHFLOWER, David; OSWALD, Andrew; STUTZER, Alois. Latent entrepreneurship across nations. European Economic Review, [s. I.], v. 45, n. 4-6, p. 680-691, 2001.

BORJAS, George J. The self-employment experience of immigrants. The Journal of Human Resources, [s. I.], v. 21, n. 4, p. 485-506, 1986.

BORJAS, George J.; BRONARS, Stephen. Consumer Discrimination and Self-Employment. Journal of Political Economy, [s. I.], v. 97, n. 3, p. 581-605, 1989.

CALVO, Guillermo A.; WELLISZ, Stanislaw. Technology, Entrepreneurs, and Firm Size. The Quarterly Journal of Economics, [s. I.], v. 95, n. 4, p. 663, 1980.

CAMARGO NETO, Roque Pinto et al. Condicionantes do empreenderismo no Brasil: uma análise regional. Revista Brasileira de Estudos Regionais e Urbanos, [s. I.], v. 11, n. 4, p. 447-466, 2017.

CÉSPEDES, Carlos Hrenán; FOCHEZATTO, Adelar. Determinantes do empreendedorismo nos Municípios do Rio Grande do Sul-Brasil: Uma perspectiva espacial. Revista ESPACIOS, [s. I.], v. 37, n. 22, 2016.

DOLTON, P. J.; MAKEPEACE, G. H. SELF EMPLOYMENT AMONG GRADUATES. Bulletin of Economic Research, [s. I.], v. 42, n. 1, p. 35-54, 1990.

EVANS, David S.; LEIGHTON, Linda S. Some Empirical Aspects of Entrepreneurship. The American Economic Review, [s. I.], v. 79, n. 3, p. 519-535, 1989.

FRITSCH, Michael; RUSAKOVA, Alina. Entrepreneurial Choice across Occupations. Working Paper, [s. I.], 2011.

GEM. Empreendedorismo no Brasil - Relatório Executivo. Empreendedorismo no Brasil - Relatório Executivo, [s. I.], v. 21 , p. 1-15, 2015.

GILL, Andrew M. Choice of employment status and the wages of employees and the self-employed: Some further evidence. Journal of Applied Econometrics, [s. I.], v. 3, n. 3, p. 229-234, 1988. Disponível em: <http://doi.wiley.com/10.1002/jae.3950030306>. Acesso em: 4 dez. 2018.

GUJARATI, Damodar N.; PORTER, Dawn C. Econometria básica. $5^{\mathrm{a}}$ ed. 2011.

HAMMARSTEDT, Mats. Predicted earnings and the propensity for self-employment. International Journal of Manpower, [s. I.], v. 30, n. 4, p. 349-359, 2009. Disponível em: <https://www.emeraldinsight.com/doi/10.1108/01437720910973043>. Acesso em: 4 dez. 2018.

HÖHER, Ricardo; LIMA, Mário Jaime Gomes De; FOCHZATTO, Adelar. Determinantes do empreendedorismo no Rio Grande do Sul: uma análise espacial. Revista Brasileira de Desenvolvimento Regional, [s. I.], v. 5, n. 3, 2017.

HOLTZ-EAKIN, D.; JOULFAIAN, D.; ROSEN, H. S. Entrepreneurial Decisions and Liquidity Constraints. In: NATIONAL BUREAU OF ECONOMIC RESEARCH, Anais. 1993. Disponível em: <http://www.nber.org/papers/w4526>

HOLTZ-EAKIN, D.; JOULFAIAN, D.; ROSEN, H. S. Sticking it Out: Entrepreneurial Survival and Liquidity Constraints. Journal of Political Economy, [s. I.], v. 102, n. 1, p. 53-75, 1994.

IBGE. Instituto Brasiliero de Geografia e Estatística. Pesquisa Nacional de Amostra por Domicílio (PNAD) 2015. 2015. Disponível em: <https://ww2.ibge.gov.br/>.

LEE, Sam Youl; FLORIDA, Richard; ACS, Zoltan. Creativity and Entrepreneurship: A Regional Analysis of New Firm Formation. Regional Studies, [s. I.], v. 38, n. 8, p. 879-891, 2004.

LINDH, Thomas; OHLSSON, Henry. Self-Employment and Windfall Gains: Evidence from the Swedish Lottery. The Economic Journal, [s. I.], v. 106, n. 439, p. 1515-1526, 1996.

LUCAS, Robert. On the Size Distribution of Business Firms. Bell Journal of Economics, [s. I.], v. 9, n. 2, p. 508-523, 1978.

MENEZES, Gabrielito Rauter. Ensaios Sobre Economia do Empreendedorismo. 2015. Universidade Federal do Rio Grande do Sul, [s. I.], 2015.

PARKER, Simon. The Economics of Self-Employment and Entrepreneurship. Cambridge ed. Cambridge. 2004.

PARKER, Simon C. The economics of entrepreneurship. First ed. [s.I.] : Cambridge University Press, 2009.

PARKER, Simon C. The economics of entrepreneurship. 2nd Editio ed. [s.I.] : Press, Cambridge University, 2018.

REES, H.; SHAH, A. Empirical Analysis of Self-Employment in the U.K. Journal of Applied Econometrics, [s. I.], v. 1, n. 1, p. 95-108, 1986.

REYNOLDS, Paul; STOREY, David J.; WESTHEAD, Paul. Cross-national Comparisons of the Variation in New Firm Formation Rates. Regional Studies, [s. I.], v. 28, n. 4, p. 443-456, 1994.

SANTOS, Gilnei C. et al. Mercado de trabalho e rendimento no meio rural brasileiro. Economia Aplicada, [s. I.], v. 14, n. 3, p. 355-379, 2010.

SCHUMPETER, Joseph A.; OPIE, Redvers. The theory of economic development; an inquiry into profits, capital, credit, interest, and the business cycle,. [s.I.] : Harvard University Press, 1934. v. 46

SLUIS, J.; PRAAG, Van Der; VIJVERBERG, W. Entrepreneurship Selection and Performance: A Meta-Analysis of the Impact of Education in Developing Economies. The World Bank Economic Review, [s. I.], v. 19, n. 2, p. 225-261, 2005. 
TAYLOR, M. P. Earnings, Independence or Unemployment: Why Become Self-Employed? Oxford Bulletin of Economics and Statistics, [s. I.], v. 58, n. 2, p. 253-266, 1996.

WIT, Gerrit; WINDEN, Frans Van. An empirical analysis of self-employment in the Netherlands. Economics Letters, [s. I.], v. 32, p. 97-100, 1990.

WOOLDRIDGE, Jeffrey M. Econometric Analysis of Cross Section and Panel Data. Second edi ed. Cambridge. 2010.

YOON, In-Jin. On My Own: Korean Businesses and Race Relations in America. University of Chicago Press, Chicago, p. 274, 1997. 